\title{
Bidirectional Switching of Near IR Emitting Boradiazaindacene Fluorophores
}

2008

Vol. 10, No. 16

$3401-3403$

\section{Erhan Deniz, ${ }^{\dagger}$ G. Ceyda Isbasar, ${ }^{\dagger}$ Ö. Altan Bozdemir," Leyla T. Yildirim, ${ }^{\ddagger}$}

Aleksander Siemiarczuk, ${ }^{\S}$ and Engin U. Akkaya ${ }^{*, I I}$

Department of Chemistry, Middle East Technical University, Ankara,

Turkey, TR-06531, Department of Enginering Physics, Hacettepe University,

Beytepe, 06531, Ankara, Turkey, PTI Fast Kinetics Laboratory, 347 Consortium Court,

London, Ontario, N6E 2S8 Canada, and Department of Chemistry and UNAM-Institute

of Materials Science and Nanotechnology, Bilkent University, Ankara,

Turkey, TR-06800

eua@fen.bilkent.edu.tr

Received May 27, 2008

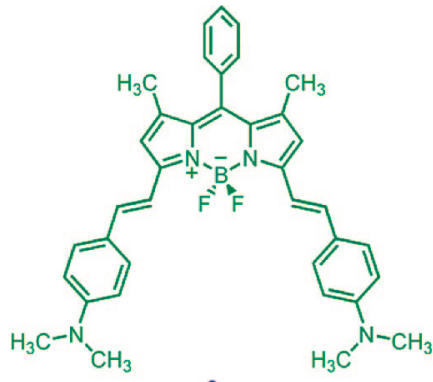

3

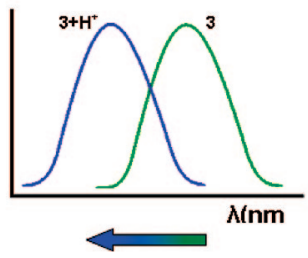

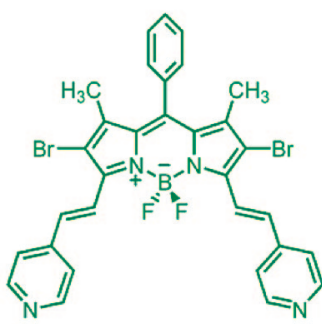

4

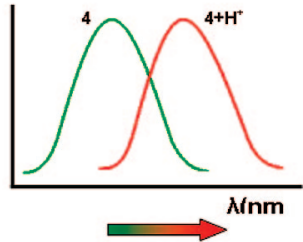

Two novel distyryl-boradiazaindacene dyes with dimethylaminostyryl and pyridylethenyl substituents display opposite spectral shifts on protonation with TFA in organic solvents. This bidirectional switching of the dyes can be shown to be directly related to ICT donor and acceptor characteristics of the substituents attached to the BODIPY core. The observed spectral response of these dyes could be very useful in the design of novel NIR fluorescent ratiometric probes for $\mathrm{pH}$.

Boradiazaindacenes (BODIPY or boradipyrrin dyes) are interesting fluorophores ${ }^{1}$ with many applications in fields as diverse as fluorescent labels, ${ }^{2}$ chemosensors, ${ }^{3}$ light harvesting

\footnotetext{
Middle East Technical University.

Hacettepe University.

$\S$ PTI Fast Kinetics Laboratory.

"Bilkent University.
}

systems, ${ }^{4}$ and photodynamic therapy. ${ }^{5}$ Their high quantum yields (typically $0.6-1.0$ ) and large extinction coefficients (60 000-80 $000 \mathrm{M}^{-1} \mathrm{~cm}^{-1}$ ) are the two main reasons for their widespread utilization. The typical peak emission wavelength of an 8-phenyl-substituted boradiazaindacene is around $510-520 \mathrm{~nm}$, which is a significantly shorter wavelength region than what would be required for a fluorophore 
compatible with biological media. This is because of high levels of scattering and significant background emission (autofluorescence) resulting from natural fluorophores. ${ }^{6}$ In recent years, a number of research groups demonstrated that boradiazaindacenes have remarkably rich chemistry, ${ }^{7}$ making these dyes amenable to chemical modifications at many positions of the boradiazaindacene core. Recently, we have shown that double styryl substitution at 3 and 5 positions yields long wavelength absorbing and emitting BODIPY dyes. ${ }^{5,7 f}$ In this study, to impart an acid switchable character to these extended conjugation dyes, we targeted boradiazaindacene dyes with pyridyl and 4-dimethylaminophenyl functionalities. To that end, 4-dimethylaminobenzaldehyde was reacted with 1,3,5,7-tetramethyl-8-phenylboradiazaindacene under azeotropic removal of water from the reaction mixture. Distyryl-substituted fluorophore $\mathbf{3}$ was obtained in satisfactory yields after chromatographic purification procedures (Scheme 1). However, the reaction with 4-pyridinecarboxaldehyde did not proceed at all, under the same conditions. To increase the acidity of the methyl groups, as we have shown ${ }^{7 f}$ earlier that this improves the chances of Knoevenagel condensation, we brominated the dye $\mathbf{1}$ at the 2 and 6 positions. Following this derivatization, compound 4 was obtained in very good yields by the condensation of the brominated boradiazaindacene dye 2 and 4-pyridinecarboxaldehyde (Figure 1). Single-crystal X-ray crystallography of the compound 4 reveals nearly coplanar arrangement of the pyridyl-ethenyl moieties with one of the groups slightly off the molecular plane by $10^{\circ}$. It is interesting to note that both $\mathrm{C} 7-\mathrm{H}$ and $\mathrm{C} 25-\mathrm{H}$ are in optimal distances for

(1) Recent reviews on bodipy dyes: (a) Ulrich, G.; Ziessel, R.; Harriman, A. Angew. Chem., Int. Ed. 2008, 47, 1184-1201. (b) Ziessel, R. Compt. Rend. Chim. 2007, 10, 622-629. (c) Loudet, A.; Burgess, K. Chem. Rev. 2007, 107, 4891-4932.

(2) Haugland, R. P. The Handbook-A guide to fluorescent probes and labeling technologies, 10th ed.; Invitrogen Corp., 2005.

(3) (a) Coskun, A.; Akkaya, E. U. J. Am. Chem. Soc. 2005, 127, 1046410465. (b) Rurack, K.; Kollmannsberger, M.; Resch-Genger, U.; Daub, J. J. Am. Chem. Soc. 2000, 122, 968-969. (c) Coskun, A.; Akkaya, E. U. J. Am. Chem. Soc. 2006, 128, 14474-14475. (d) Zeng, L.; Miller, E. W.; Pralle, A.; Isacoff, E. Y.; Chang, C. J. J. Am. Chem. Soc. 2006, 128, 1011. (e) Coskun, A.; Deniz, E.; Akkaya, E. U. Org. Lett. 2005, 7, 51875189. (f) Saki, N.; Dinc, T.; Akkaya, E. U. Tetrahedron 2006, 62, 27212725. (g) Coskun, A.; Turfan, B. T.; Akkaya, E. U. Tetrahedron Lett. 2003, 44, 5649-5651. (h) Ekmekci, Z.; Yilmaz, M. D.; Akkaya, E. U. Org. Lett. 2008, 10, 461-464.

(4) (a) Li, F.; Yang, S. I.; Ciringh, Y. Z.; Seth, J.; Martin, C. H.; Singh, D. L.; Kim, D.; Birge, R. R.; Bocian, D. F.; Holten, D.; Lindsey, J. L. J. Am. Chem. Soc. 1998, 120, 10001-10017. (b) Yilmaz, M. D.; Bozdemir, O. A.; Akkaya, E. U. Org. Lett. 2006, 8, 2871-2873.

(5) Atilgan, S.; Ekmekci, Z.; Dogan, A. L.; Guc, D.; Akkaya, E. U. Chem. Commun. 2006, 4398-4400.

(6) Czarnik, A. W. Chem. Biol. 1995, 2, 423-428.

(7) (a) Rurack, K.; Kollmannsberger, M.; Daub, J. Angew. Chem., Int. Ed. 2001, 40, 385-387. (b) Goze, C.; Ulrich, G.; Mallon, L. J.; Allen, B. D.; Harriman, A.; Ziessel, R. J. Am. Chem. Soc. 2006, 128, 10231-10239. (c) Ziessel, R.; Goze, C.; Ulrich, G.; Cesario, M.; Retailleau, P.; Harriman, A.; Rostron, J. P. Chem. - Eur. J. 2005, 11, 7366-7378. (d) Ulrich, G.; Goze, C.; Guardigli, M.; Roda, A.; Ziessel, R. Angew. Chem., Int. Ed. 2005, 44, 3694-3698. (e) Goze, C.; Ulrich, G.; Ziessel, R. Org. Lett. 2006, 8, 44444448. (f) Dost, Z.; Atilgan, S.; Akkaya, E. U. Tetrahedron 2006, 62, 84848488. (g) Baruah, M.; Qin, W.; Vallee, R. A. L.; Beljonne, D.; Rohand, T.; Dehaen, W.; Boens, N. Org. Lett. 2005, 7, 4377-4380. (h) Rohand, T.; Baruah, M.; Qin, W.; Boens, N.; Dehaen, W. Chem. Commun. 2006, 266268. (i) Rohand, T.; Qin, W.; Boens, N.; Dehaen, W. Eur. J. Org. Chem. 2006, 4658-4663. (j) Gabe, Y.; Ueno, T.; Urano, Y.; Kojima, H.; Nagano, T. Anal. Bioanal. Chem. 2006, 386, 621-626. (k) Li, L. L.; Han, J. Y.; Nguyen, B.; Burgess, K. J. Org. Chem. 2008, 73, 1963-1970. (1) Thivierge, C.; Bandichhor, R.; Burgess, K. Org. Lett. 2007, 9, 2135-2138.
Scheme 1. Synthesis of the Novel Dyes 3 and $\mathbf{4}$

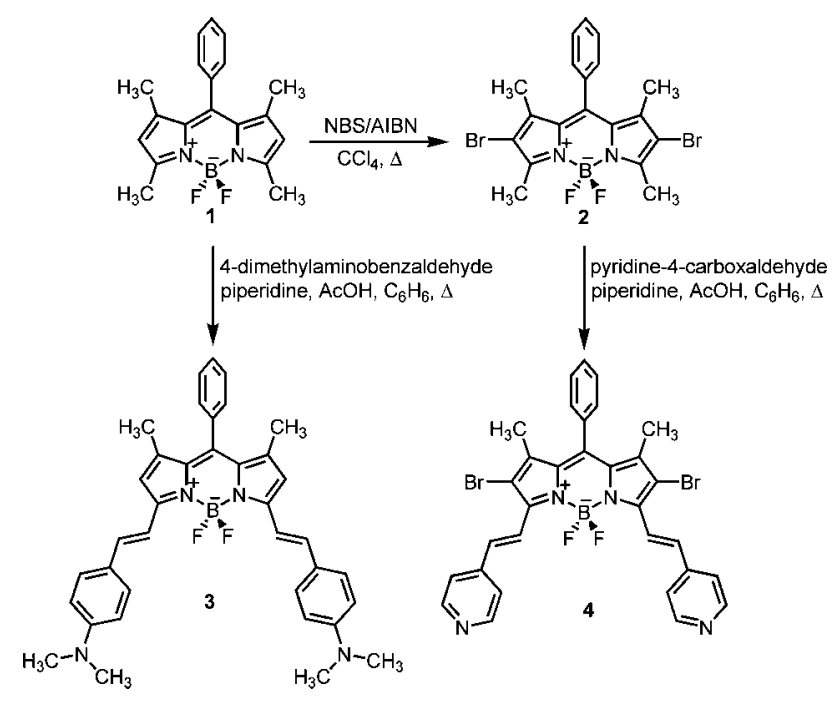

hydrogen bonding to both of the fluorine atoms on the $\mathrm{BF}_{2}$ bridge. All four relevant $\mathrm{C}-\mathrm{H}-\mathrm{F}$ bond angles are very close to $120^{\circ}$.

Both of the dyes $\mathbf{3}$ and $\mathbf{4}$ form green solutions in chloroform. Their absorption spectra are shown in Figures 2 and 3. The fluorophore $\mathbf{3}$ has an absorption peak at 700 $\mathrm{nm}$, whereas the pyridyl derivative $\mathbf{4}$ has a peak at $620 \mathrm{~nm}$.

Both fluorophores show certain characteristics of ICT (internal charge transfer) dyes. The absorption spectra show aggregation related peaks in solvents more polar than chloroform. The acid switchability was studied in chloroform. When a small amount of TFA was added to a chloroform solution of dye $\mathbf{3}$, a spectrum corresponding to the doubly protonated species $\left(3-2 \mathrm{H}^{+}\right)$was obtained. The addition of a larger excess of TFA creates some further protonated charge transfer species (Supporting Information). The emission spectra parallel the changes in the absorption spectra,

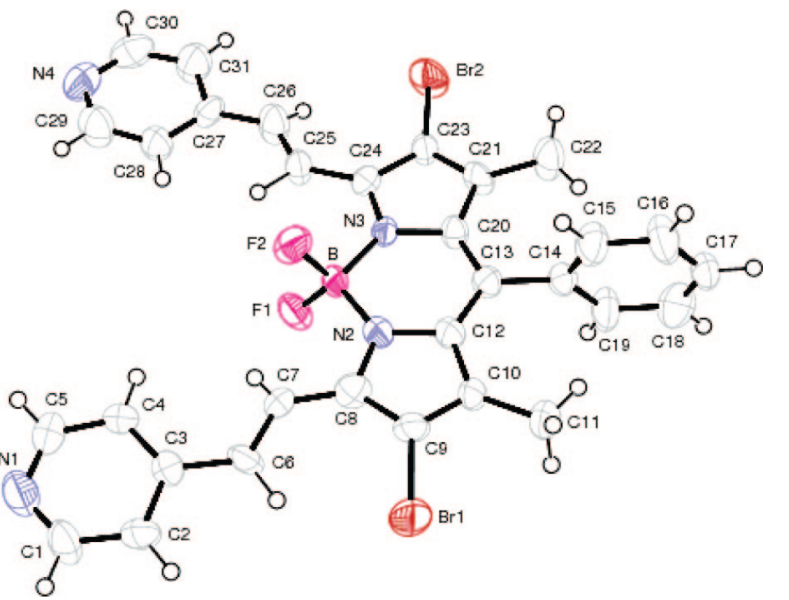

Figure 1. X-ray diffraction structure of the distyrylboradiazaindacene 4. 

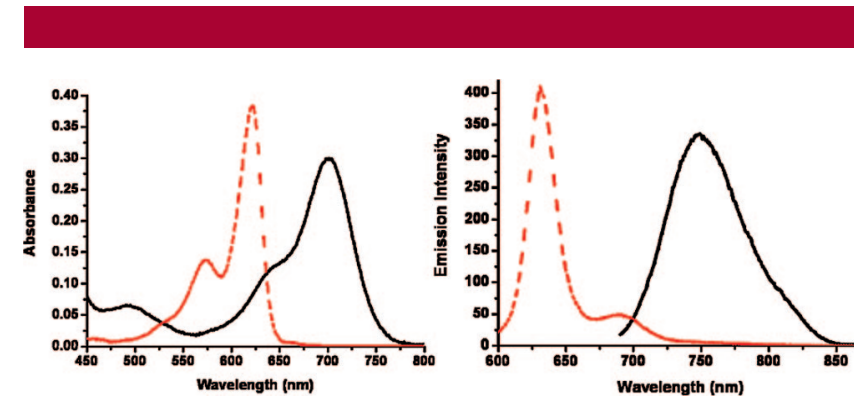

Figure 2. Absorption (left) and emission (right) spectra of compound $\mathbf{3}$ in response to the addition of a small aliquot of TFA. Black solid curve, $\mathbf{3}$; red dashes $\mathbf{3}+2 \mathrm{H}^{+}$. The concentration of the dye was adjusted to $4.3 \mu \mathrm{M}$ for absorbance and $1.2 \mu \mathrm{M}$ for fluorescence measurements.

and similar changes are not observed by the addition of simple H-bond donors like ethanol into the chloroform solution. On the contrary, the absorption peak shows no shift upon changing the solvent from pure $\mathrm{CHCl}_{3}$ to $20 \% \mathrm{EtOH}$ in $\mathrm{CHCl}_{3}$; the emission spectrum shows only a small solvatochromic shift of $8 \mathrm{~nm}$.

Thus, we conclude that two different protonation states ( \pm TFA) yield two different sets of absorption and emission spectra. The corresponding emission peaks for $\mathbf{3}, \mathbf{3}-2 \mathrm{H}^{+}$, are at 753 and $630 \mathrm{~nm}$, respectively. A blue shift on the addition of TFA is expected, considering that as an ICT donor group dimethylamino functionality becomes a considerably less effective electron donor on protonation, and this results in a blue shift. We should also point out that the absorbance and the emission properties of $3-2 \mathrm{H}^{+}$closely resemble the simple styryl derivative reported earlier. ${ }^{7 \mathrm{a}}$ The pyridyl-substituted dye $\mathbf{4}$ shows a different behavior: gradual addition of a small amount of TFA results in a single distinct but red-shifted spectrum. The absorption peak at $620 \mathrm{~nm}$ moves to $660 \mathrm{~nm}$ on TFA addition. This red shift is not surprising since the pyridyl groups are electron-withdrawing substituents for the ICT scenario, and in such fluorophores, it is known that any event making the electron-acceptor group

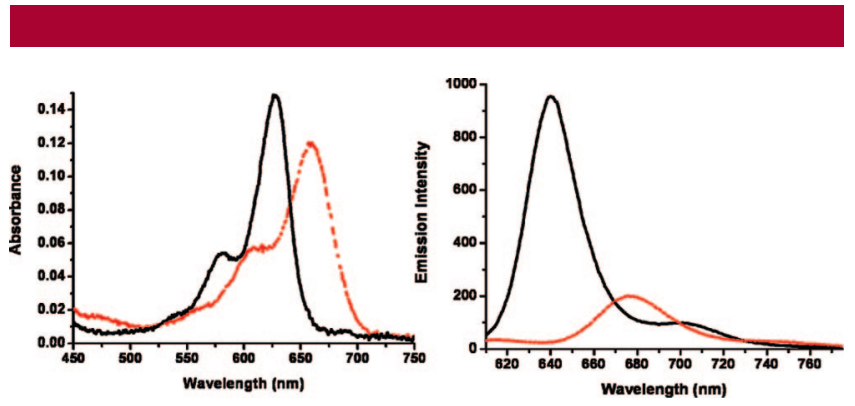

Figure 3. Absorption (left) and emission (right) spectra of compound $\mathbf{4}$ in response to a small aliquot of TFA. Black solid curve, $\mathbf{4}$; red dashes $\mathbf{4}+2 \mathrm{H}^{+}$. The concentration of the dye was adjusted to $1.2 \mu \mathrm{M}$ for absorbance and $0.8 \mu \mathrm{M}$ for fluorescence measurements. a stronger electron acceptor (like protonation or cation binding) produces a bathochromic change. Thus, the emission spectrum shows just one red-shifted peak at $677 \mathrm{~nm}$ on TFA addition.

Time-resolved fluorescence spectroscopy reveals emissive species with different lifetimes. Pyridyl derivative $\mathbf{4}$ shows a single exponential decay with a lifetime of $4.29 \mathrm{~ns}$. The protonated (doubly) species $\left(4+2 \mathrm{H}^{+}\right)$has a shorter lifetime of $3.06 \mathrm{~ns}$, which is in accordance with the general principle of bathochromic shifts increasing nonradiative rate constants.

Compound $\mathbf{3}$ has an emissive lifetime of $2.7 \mathrm{~ns}$. When a very small aliquot of TFA was added $(10 \mu \mathrm{L})$, while the original emission disappears, a brighter emission from a new ionic species $\left(3+2 \mathrm{H}^{+}\right)$becomes prominant. The recovered emission lifetimes are 1.20 and $3.6 \mathrm{~ns}$, respectively. The shorter lifetime component is most likely due to the formation of charge transfer species, and the longer lifetime is due to the doubly protonated dye.

In conclusion, there seems to be no limitation to the straightforward functionalization of the BODIPY dyes through Knoevenagel reactions of the moderately acidic methyl substituents. It is evident that appropriate functionalization of the distryl-BODIPY dyes would yield near-IR emitting fluorescent probes for $\mathrm{pH}$ and other ions simply by judicious selection of the reacting aldehyde and thus the styryl substituent.

Table 1. Selected Interatomic Distances $(\AA)$ and Angles for Compound $\mathbf{3}$

\begin{tabular}{lc}
\hline \multicolumn{1}{c}{ atomic nuclei } & distances/angles \\
\hline $\mathrm{B}-\mathrm{F} 1$ & $1.372(13)$ \\
$\mathrm{C} 6-\mathrm{C} 7$ & $1.435(13)$ \\
$\mathrm{C} 3-\mathrm{C} 6$ & $1.464(13)$ \\
$\mathrm{F} 1-\mathrm{B}-\mathrm{F} 2$ & $108.9(9)$ \\
$\mathrm{F} 1-\mathrm{B}-\mathrm{N} 2$ & $112.1(9)$ \\
$\mathrm{F} 2-\mathrm{B}-\mathrm{N} 2$ & $109.0(9)$ \\
$\mathrm{C} 23-\mathrm{C} 24-\mathrm{C} 25-\mathrm{C} 26^{a}$ & $5(2)$ \\
$\mathrm{C} 9-\mathrm{C} 8-\mathrm{C} 7-\mathrm{C} 6^{a}$ & $-10(2)$ \\
$\mathrm{C} 19-\mathrm{C} 14-\mathrm{C} 13-\mathrm{C} 12^{b}$ & $90.8(14)$ \\
$\mathrm{C} 15-\mathrm{C} 14-\mathrm{C} 13-\mathrm{C} 20^{b}$ & $91.3(13)$
\end{tabular}

${ }^{a}$ Torsion angles for the styryl groups. ${ }^{b}$ Torsion angles for the 8-phenyl substituent.

Acknowledgment. This work was supported by the Turkish Scientific and Technical Research Council (TUBITAK) and Turkish Academy of Sciences (TUBA).

Supporting Information Available: Syntheses, experimental details, time-resolved spectroscopy data, additional crystallographic data, and the CIF file for compound 4 . This material is available free of charge via the Internet at http://pubs.acs.org.

OL801062H 